\title{
Osnove motivacijskega intervjuja
}

\author{
Darja Boben Bardutzky \\ Zdravstveni dom Trbovlje \\ darja.b.bardutzky@gmail.com \\ Vita Poštuvan \\ Univerza na Primorskem \\ vita.postuvan@upr.si
}

Do pogovora o spremembi vedenja pride takrat, ko svetovalec in/ali klient ugotovita, da je klientovo vedenje pomembno za njegovo zdravje in življenje. Če je klient nemotiviran za spremembe ali za upoštevanje nasvetov, lahko svetovalec dobi občutek nemoči in klientu ne bo moč pomagati. Avtorja metode motivacijskega intervjuja (William Miller in Stephen Rollnick) sta prepričana, da je vsakdo motiviran za nekaj, vloga svetovalca pa je ustvariti takšen odnos, kjer klientu ne bo potrebno biti v obrambni drži. Na motivacijo za spremembe je možno vplivati, in sicer predvsem z načinom, kako se pogovarjamo s klienti o njihovem zdravju. Nekateri pristopi povečujejo motivacijo in so zato za takšne primere funkcionalnejši, drugi pa spodbujajo obrambne mehanizme. Motivacijski intervju ni tehnika, s katero bi manipulirali z ljudmi, da bodo počeli nekaj, česar ne želijo, temveč je klinična veščina, s katero ljudem pomagamo, da se zavedo svoje lastne motivacije za spremembe. V prispevku so opisani ključni elementi motivacijskega intervjuja, kot so filozofija, načela, strategije in govor, ki napoveduje spremembe. Motivacijski intervju spodbuja sodelovanje, izvabljanje motivacijskih izjav in spoštovanje klientove avtonomije, pri čemer so ključni empatija, obravnava klientove ambivalentnosti ter reflektivno poslušanje.

\section{Izhodišča}

Pogovor o spremembah vedenja je relevanten, ko terapevt in klient $\mathrm{v}$ okviru medsebojnega dela ugotovita, da klientovo vedenje pomembno vpliva na njegovo zdravje. Spremembe vedenja se lahko nanašajo na željo po:

- pozitivnih spremembah, kot so redno jemanje predpisanih zdravil, umivanje zob, drugačna dieta, rekreacija;

- prenehanju škodljivih vedenj, kot so kajenje, opijanje, drogiranje, pretirano delo, hitra prehrana;

- večji splošni skrbi na zdravstvenem področju, npr. pitje zadostne tekočine, uporaba kontracepcijskih sredstev, slušnega aparata ... 
Kadar je klient videti nemotiviran za spremembe ali za upoštevanje nasvetov, lahko osebje predvideva, da je nekaj narobe in podvomi v možne spremembe situacije. Predpostavke o nemotiviranem klientu so običajno napačne, kajti nihče ni popolnoma nemotiviran. Izhodišče motivacijskega intervjuja je ravno nasprotno, in sicer da je na motivacijo za spremembe možno vplivati in je odvisna predvsem od odnosa terapevt - klient (Rollnick idr., 2008).

\section{Vloga psihologa oz. terapevta pri motiviranju za spremembe}

Način, kako se pogovarjamo s klienti, vpliva na njihovo osebno motiviranost za vedenjske spremembe in ima lahko ima dolgoročen vpliv na njihovo zdravje. Namesto da privzema ideje o nemotiviranem klientu, naj bi se terapevt oz. psiholog zavedal, da imamo vsi potrebe, želje, cilje, aspiracije, četudi morda to na prvi pogled pri kakšem klientu ni takoj očitno (Rollnick idr., 2008).

Med terapevti in njihovimi pristopi obstajajo razlike. Miller in Taylor (1980) sta sledila devetim terapevtom skozi šestmesečno obdobje, pri čemer so bili ocenjevani glede na svoj pristop. Rezultati študije so pokazali, da so lahko $\mathrm{z}$ relativno dobro verjetnostjo napovedovali uspešnost terapije (ki je bila namenjena zdravljenju odvisnosti od alkohola) glede na empatičnost terapevta. Empatičnejši terapevti so imeli večjo verjetnost za pozitivne izide terapije, učinek pa se je obdržal tudi po enem letu (Miller in Baca, 1983). Podobne študije so ponovili pri terapevtih, ki so uporabljali konfrontacijski način, in ugotovili, da bolj ko je terapevt konfrontiral ljudi, večja je bila verjetnost, da so klienti nadaljevali s pitjem (Miller idr., 1993).

Študije hkrati ugotavljajo tudi, da na odziv na terapijo lahko vpliva že terapetov ton; vpliva je lahko pozitiven ali negativen, zato je v primerih situacij, kjer ni mogoče zagotoviti empatičnega odnosa, učinkovitejša uporaba pisnih materialov (Miller in Taylor, 1980). Chafetz idr. (1962; 1964) je s sodelavci v dveh študijah ugotavljal vpliv empatičnosti na intoksicirane kliente, sprejete na urgenci. Tisti, ki so bili deležni empatične terapevtske seanse, so bili desetkrat bolj zainteresirani za zdravljenje odvisnosti (65$78 \%$ ) v primerjavi s tistimi, ki so doživeli klasičen pristop zdravnika (tam je bila odzivnost za zdravljenje med 5 in $6 \%$ ). Ko so spremljali vpliv takšnih pogovorov na sprejeme v programe zdravljenja odvisnosti, je bila razlika še večja (45-56\% proti 1-0\%).

\section{Pripravljenost za spremembe}

Klienti se razlikujejo glede na pripravljenost za spreminjanje (DiClemente in Prochaska, 1998; Prochaska idr., 1992; Miller in Butler, 2008; DiCle- 
mente in Hughes, 1990). V procesu spreminjanja velikokrat najdemo spodnje značilnosti:

- Ambivalentnost (razdvojenost) glede sprememb je normalna, saj je spremembe težko izvesti, čeprav se klienti zavedajo njihovih pozitivnih učinkov. Negotovosti ne smemo doživljati kot težavo, temveč raje kot del procesa, ki se ga lahko tudi spretno vključi v terapevtsko delo.

- Spremembe običajno ne potekajo linearno, temveč po prvih korakih doživijo poslabšanje, saj se klienti (za nekaj časa) vrnejo k starim navadam, preden se vedenje zares spremeni.

- Pripravljenost za spremembe ni nekaj statičnega, temveč ima lahko različne oblike, nanjo pa lahko vpliva tudi terapevt.

- Pozornost, usmerjena v pripravljenost za spremembe, je vitalnega pomena za izvedbo sprememb, zato se temu bolj posvetimo. Potrebno je oceniti prepričanje o zmožnosti uresničenja sprememb in njihovega zaznanega pomena.

Največji vpliv na motivacijo za spremembe imajo terapevti odvisnikov, pri nekaterih ostalih psihoterapevtskih izidih študije kažejo manjšo konsistentnost v možnostih vplivanja (Miller, 2000).

Obenem lahko poudarimo pomen sprememb izven terapevtske obravnave. V splošni populaciji je prevalenca motenj veliko večja od vseh razpoložljivih virov pomoči, hkrati pa veliko ljudi okreva tudi brez terapije, kar imenujemo spontana remisija. Naravne spremembe se dogajajo v podobnem procesu kot $\mathrm{v}$ terapiji, le časovni okvirji so navadno precej daljši (Miller, 2000; DiClemente in Prochaska, 1998).

\section{Elementi motivacijskega intervjuja}

Najpomembnejši elementi motivacijskega intervjuja so razvrščeni v štiri skupine (Rollnick idr., 2008; Rosengren, 2009):

1. filozofija motivacijskega intervjuja;

2. načela motivacijskega intervjuja;

3. strategije motivacijskega intervjuja;

4. govorica, ki napoveduje spremembe (angl. change talk).

Te elemente najdemo tudi $\mathrm{v}$ drugih terapevtskih pristopih, religijah oz. filozofijah, vendar je njihova kombinacija edinstvena za motivacijski intervju. 
Filozofija motivacijskega intervjuja

Motivacijski intervju ni tehnika, s katero bi manipulirali z ljudmi, da bodo počeli nekaj, česar ne želijo, temveč je klinična svetovalna veščina, ki ljudem omogoči, da se zavedo svojih lastnih zdravih motivov, potrebnih za odločitev o spremembi vedenja. Za motivacijski intervjuju je značilnejš vodenje kot predpisovanje, bolj ples kot rokoborba in poslušanje vsaj toliko kot pripovedovanje. Najpomembnejši pojmi, ki opišejo filozofijo motivacijskega intervjuja, so: sodelovanje, izvabljanje in spoštovanje klientove avtonomije.

- Sodelovanje. Motivacijski intervju temelji na kooperativnem partnerstvu med terapevtom in klientom. Namesto neenakega odnosa glede na pozicijo moči, v katerem strokovnjak usmerja pasivnega klienta in mu dopoveduje, kaj naj dela, motivacijski intervju omogoča aktiven, sodelujoč pogovor, ki oblikuje proces skupnega odločanja. Takšna pozicija je pomembna, saj omogoča spremembe, ki vplivajo na zdravje klienta; nenazadnje je klient tisti, ki bo izvajal te spremembe.

- Izvabljanje. Včasih svetovalne službe, sistem zdravstva ali drugih podpornih sistemov dajejo občutek zagotavljanja vsega, kar klient potrebuje (zdravila, informacije, razlage ali veščine). Motivacijski intervju, obratno, poskuša odkriti in iz klienta izvabiti njegove lastne vire za spreminjanje. Klient mogoče ni motiviran točno za to, kar mi želimo od njega - ima pa zagotovo svoje osebne cilje, vrednote, aspiracije in sanje ... Bistveni del umetnosti motivacijskega intervjuja je povezovanje nujnih sprememb vedenja s klientovimi vrednotami, skrbmi, potrebami...

- Spoštovanje klientove avtonomije. Motivacijski intervju zahteva neke vrste nenavezanosti na rezultate, kar ne pomeni odsotnosti skrbnosti, pač pa spoznanje, da ljudje lahko izbirajo (in dejansko izbirajo) smeri svojega življenja. Prepoznavanje in spoštovanje te avtonomije je ključni element pri omogočanju spreminjanja. Če namreč skušamo uveljavljati spremembe prehitro, se nekaj v človekovi naravi upira zaradi občutka prisile in ukazovanja. Paradoksalno včasih prav pravica do nespreminjanja omogoči spreminjanje.

\section{Načela motivacijskega intervjuja}

Rollnick idr. so med načela motivacijskega intervjuja sprva šteli izražanje empatije, vzpodbujanje samoučinkovitosti, jačanje nasprotij in specifično (nežno) obravnavo odporov. 
Kasneje so to posodobili v naslednje sklope (Rollnick idr., 2008; Rosengren, 2009):

- Upreti se refleksu urejanja drugih. Ljudje, ki delujejo na področju pomoči drugim, imajo običajno močno željo urejati, pozdraviti, preprečiti škodo in promovirati zdravo življenje. Ta namen ima lahko večkrat obraten učinek, torej da rezultati teh želja niso tako dobri, kot bi si želeli. To ne pomeni, da je z ljudmi, ki prejemajo pomoč, nekaj narobe, da so neposlušni, leni ali živijo v obupnem zanikanju. Takšne razlike so bolj posledica tega, da se ljudje upiramo prepričevanju, še posebno, če smo razdvojeni. Ambivalentnost velikokrat rezultira v vztrajanju v sedanjih okvirjih delovanja (Rollnick idr., 2008; Rosengren, 2009).

Obrambe (odpor) predstavljajo aktiven proces, ki se sproži, kadar nekoga zasujemo z razlogi za spreminjanje. Študije so pokazale, da nekatera vedenja terapevtov jačajo obrambe in odpore. Med temi so: prepričevanje klienta, da ima problem, utemeljevanje dobrih strani spremembe, poučevanje klienta, kako naj se spremeni, in opozarjanje na posledice, ki bodo sledile, če se klient ne spremeni (Rollnick idr., 2008).

- Razumevanje klientove motivacije. Klientovi razlogi za spremembe bodo sprožili spremembe vedenja. Zato terapevta zanimajo klientove skrbi, vrednote in motivi, pri čemer mora paziti, da ne vsiljuje svojih. Postopoma klienta usmerja k osveščanju razkoraka med tem, kaj si želi zase, in tem, kako njihovo sedanje vedenje vpliva na to. Klient mora biti tisti, ki ubesedi razloge za spremembo - ne terapevt (Rollnick idr., 2008; Rosengren, 2009).

- Poslušanje klienta. Motivacijski intervju vključuje najmanj toliko poslušanja kot informiranja. Morda je normalno pričakovanje, da ima strokovnjak odgovore na vprašanja in jih bo posredoval klientu, a ko gre za spreminjanje vedenja, odgovore najdemo pri klientu. Da jih najdemo, je potrebno precej poslušanja. Dobro poslušanje je kompleksna klinična veščina in je veliko več kot le postaviti vprašanje in biti tiho, dokler klient ne odgovori. Dobro poslušanje vključuje empatijo, sprejemanje, optimistično držo (Rollnick idr., 2008; Rosengren, 2009).

- Jačanje klienta. Klientu pomagamo raziskovati, kako lahko sam spremeni stvari na bolje. Njegove lastne ideje in viri so ključnega pomena. Klient je terapevtov svetovalec pri tem, kako naj se mu pomaga, da 
Preglednica 1 Znanja in kompetence psihologov za uporabo elementov motivacijskega intervjuja

\begin{tabular}{|c|c|}
\hline Znanja & Kompetence \\
\hline - Teorija motivacije & - Prepoznavanje notranjih motivov za spremembe \\
\hline - Osnove motivacijskega intervjuja & - Zavedanje lastne motiviranosti \\
\hline $\begin{array}{l}\text { - Aplikacija motivacijskega inter- } \\
\text { vjuja na različna področja }\end{array}$ & $\begin{array}{l}\text { - Reflektiranje in razumevanje ovir za komunika- } \\
\text { cijo }\end{array}$ \\
\hline
\end{tabular}

doseže spremembe za izboljšanje življenja. Pomembno je, da terapevt jača upanje klienta, da so spremembe možne in da bodo učinkovite za njegovo zdravstveno stanje (Rollnick idr., 2008; Rosengren, 2009).

Temeljne veščine MI

Temeljne veščine motivacijskega intervjuja so podobne drugim terapevtskim pristopom. Med drugim so to terapevtska orodja, ki pomagajo zgraditi odnos, raziskati skrbi, posredovati empatijo. Med veščine sodijo postavljanje odprtih vprašanj, afirmacije, reflektivno poslušanje, povzemanje itd. (Rollnick idr., 2008; Rosengren, 2009).

Govor, ki napoveduje spremembe (»change talk«)

Motivacijski intervju unikatno daje izjemen poudarek izzivanju specifičnega klientovega govora. Gre za govorico (jezik), ki napoveduje spremembe. Ta postopek temelji na predpostavki, da bo klient lažje izpeljal spremembe, če bo o tem govoril s terapevtom. Še posebej je to pomembno $\mathrm{v}$ ambivalentni fazi uvajanja sprememb (Rollnick idr., 2008; Rosengren, 2009).

Študije so pokazale, da jakost in trajanje govorice spreminjanja napovedujeta pristanek oz. zavezo za spremembe, ta pa napoveduje vedenjske spremembe. Motivacijski intervju pomaga klientom, da ubesedijo, da so se sposobni spremeniti, da se želijo spremeniti, zakaj se želijo spremeniti in kaj jim bo sprememba prinesla - razloge in sposobnosti za spreminjanje (Rollnick idr., 2008; Rosengren, 2009).

\section{Kompetence za uporabo elementov motivacijskega intervjuja}

Preglednica 1 povzema znanja in kompetence, ki so ključni za psihologovo delo pri uporabi elementov motivacijskega intervjuja.

Principe motivacijskega intervjuja je lažje doživeti kot o njih teoretično pisati. Za urjenje veščin za psihologe je dobro, da kvalitete veščin prepoznamo pri drugih in uvidimo njihov vpliv nase. To omogoča transfer na 
delo s klienti. Spodnje aktivnosti lahko pomagajo razvijati opisane kompetence in znanja.

\section{Prepoznava virov za spremembe}

Abmivalentnost, nelinearnost in usmerjanje pozornosti na spremembe $\mathrm{v}$ motivaciji so koraki za prepoznavo virov v procesu spreminjanja. Pomembno je, da v vsakodnevnem življenju opazimo lastne vire, kajti tako lažje opazimo slednje tudi pri drugih ljudeh.

Aktivnost. Najljubši učitelj ali mentor.

Pomislite na osebo, ki vas je motivirala za učenje, inspirirala, da ste naredili kakšno stvar boljše, kot bi sicer, $\mathrm{v}$ vas prebudila željo po rasti in napredku. Pomislite na vaš odnos z osebo (če ne morete izbrati ene osebe, jih imate lahko v mislih več).

Za refleksijo premislite:

- Kdo in kakšna je bila ta oseba?

- Kako ste se počutili ob osebi?

- Kaj je pomagalo k vaši rasti zaradi te osebe? Kaj vas je inspiriralo, da ste dali vse od sebe?

- Na kakšen način je pristopala do vas?

- Kako ste se odzvali na pristope osebe?

Ko ste preučili značilnosti osebe, poskusite $\mathrm{v}$ tem prepoznati katero od značilnosti motivacijskega intervjuja (Rosengren, 2009).

\section{Urjenje empatije}

Empatija je del dobrega odnosa med terapevtom in klientom. Lahko jo urimo $\mathrm{z}$ različnimi aktivnostmi, predvsem pa tudi izven terapevtskih odnosov. Ko se vživimo v druge, lažje razumemo njihovo doživljanje.

Aktivnost. Vožnja z avtom - urjenje empatije kot ključnega principa znotraj motivacijskega intervjuja.

Za urjenje empatije uporabite vožnjo $z$ avtomobilom. Ob vožnji z avtom, na avtobusu ali drugem prevoznem sredstvu opazujte promet. Prepoznajte osebo, ki je naredila tvegano potezo $\mathrm{v}$ prometni varnosti oz. je v vas vzbudila negativna čustva, npr. jezo, nestrpnost.

Se zavedate čustev, ki ste jih doživeli ob tem? Poskusite se vživeti v to osebo: poskusite pomisliti na to, kakšna zgodba je za njo, kako je 
potekal njen današnji dan in kaj je morebiti vodilo v tvegano potezo, ki ste jo pravkar videli.

Vajo nadaljujte tako dolgo, dokler ne začutite, da se čustva jeze, nelagodja, frustracij zamenjajo s sočutjem oz. razumevanjem (Rosengren, 2009).

Včasih nimamo težav, da se vživimo v klientove zgodbe, spet drugič je to težje. Poskusite prepoznati, kdaj je lažje ali težje vam.

\section{Uporaba veščin motivacijskega intervjuja}

Veščin motivacijskega intervjuja se najlažje naučimo z igro vlog oz. $\mathrm{z}$ uporabo tehnike v praksi. Dobrodošlo je, da takšne aktivnosti posnamete in si po izkušnji ogledate svoje verbalne in neverbalne veščine.

Aktivnost. Motivacijski intervju $\mathrm{z}$ vašim bližnjim ali klientom.

Poskusite izvesti motivacijski intervju. Primeri vprašanj, ki jih lahko uporabite za iztočnico:

- Čemu (zakaj, zaradi česa) bi si želeli, da se stvari spremenijo?

- Kaj si predstavljate, da bi morda naredili, če bi želeli uspeti?

- Kateri trije razlogi so tisti, zaradi katerih bi to naredili?

- Ocenite na lestvici od 1 do 10, kako pomembno je za vas, da bi to naredili?

Po izvedbi zapišite in reflektirajte izkušnjo.

- Zapišite, koliko časa ste namenili pripravi.

- Zapišite, koliko časa ste namenili izvedbi.

- Zapišite, koliko časa ste namenili refleksiji.

Refleksija:

- Kako ste se pripravili na motivacijski intervju?

- Kaj je bil namen, cilj pogovora?

- Kako bi na kratko opisali primer?

- Kako je potekala izvedba?

Napišite nekaj vaših vprašanj, refleksij, povzetkov, za katere menite, da so učinkovali. Lahko napišete tudi dobeseden del pogovora, za katerega menite, da je bil učinkovit. 
- Kaj se je pri vas dogajalo pred, med in po izvedbi pogovora (vaši občutki, vaše misli, vaše telo)?

- Kaj se vam je zdelo, da ste naredili dobro?

- Vas je kaj presenetilo?

- Ko gledate nazaj, bi kaj spremenili?

- Na katerih področjih potrebujete izkušnje, znanje, prakso?

- Kje pri vašem delu boste lahko uporabili motivacijski intervju?

\section{Zaključek}

Motivacijski intervju je ena izmed možnih tehnik, ki omogoča pozitivne spremembe vedenja ljudi z nezdravimi navadami. Psihologu lahko pomaga tako pri delu s klienti kot pri mentoriranju psihologov začetnikov. Pri njih namreč šele vzpostavljamo spretnosti, vedenjske navade in strokovne usmeritve.

\section{Literatura}

Chafetz, M. E., Blane, H. T., Abram, H. S., Golner, J. H., Hastie, E. L., in Meyers, W. (1962). Establishing treatment relations with alcoholics. Journal of Nervous and Mental Disease, 134(5), 395-409.

Chafetz, M. E., Blane, H. T., Abram, H. S., Clark, E., Golner, J. H., Hastie, E. L., in McCourt, W. F. (1964). Establishing treatment relations with alcoholics: A supplementary report. Journal of Nervous and Mental Disease, 138(4), 390-393.

DiClemente, C. C., in Hughes, S. O. (1990). Stages of change profiles in outpatient alcoholism treatment. Journal of Substance Abuse, 2(2), 217-235.

DiClemente, C. C., in Prochaska, J. O. (1998). Toward a comprehensive, transtheoretical model of change: Stages of change and addictive behaviors. V W. R. Miller in N. Heather (ur.), Treating addictive behaviors (2. izdaja, str. 3-24). Plenum.

Miller, W. R. (2000). Rediscovering fire: Small interventions, large effects. Psychology of Addictive Behaviors, 14(1), 6-18.

Miller, W. R., in Baca, L. M. (1983). Two-year follow-up of bibliotherapy and therapist-directed controlled drinking training for problem drinkers. Behavior Therapy, 14(3), 441-448.

Miller, W. R., in Taylor, C. A. (1980). Relative effectiveness of bibliotherapy, individual and group self-control training in the treatment of problem drinkers. Addictive Behaviors, 5(1), 13-24.

Miller, W. R., Benefield, R. G., in Tonigan, J. S. (1993). Enhancing motivation for change in problem drinking: A controlled comparison of two therapist styles. Journal of Consulting and Clinical Psychology, 61(3), 455-461.

Prochaska, J. O., DiClemente, C. C., in Norcross, J. C. (1992). In search of 
how people change: Applications to the addictive behaviors. American Psychologist, 47(9), 1102-1114.

Rollnick, S., Miller, W. R., in Butler, Ch. C. (2008). Motivational interviewing in health care: Helping people change behavior. The Guildford Press.

Rosengren, D. B. (2009). Building motivational interviewing skills: Practitioner workbook. The Guilford Press.

\section{Basics of Motivational Interviewing}

When counselor and client realize that something very important in client's life has gone wrong and became dangerous, they start to think and talk about the need for change. If the clients don't follow counselor's advices there is a tendency to see them as unmotivated and a counselor might feel unable to help. The authors of the method of Motivational Interviewing (William Miller and Stephen Rollnick) are convinced that everybody is motivated for something and the role of the counselor is to make such a relationship where the patient won't need to be defensive. Motivation for changes is something that can be influenced by the therapist and is the matter of how we communicate with clients about their health. Some approaches increase motivation and are thus more appropriate and others increase defense mechanisms. Motivational interviewing is not a technique for manipulating people into doing what they do not want to do. It's a skillful clinical style for eliciting from clients their own motivations for making behavioral changes. In the chapter we describe the core elements of the motivational interviewing, such as its philosophy, principles, strategies and change talk. Motivational interviewing is collaborative and evocative in spirit and is honoring of clients' autonomy. Key principles used are empathy, dealing with the ambivalence and reflective listening. 